\title{
ORIGINAL ARTICLE \\ Quality of life after spinal cord injury: a comparison across six countries
}

\author{
S Geyh ${ }^{1,2}$, C Ballert ${ }^{1,2}$, A Sinnott ${ }^{3}, S$ Charlifue ${ }^{4}$, A Catz ${ }^{5,6}, \mathrm{JM} \mathrm{D}^{\prime}$ Andrea Greve ${ }^{7}$ and MWM Post ${ }^{1,8}$
}

\begin{abstract}
Study design: An international cross-sectional study.
Objective: To examine the quality of life (QoL) of people with spinal cord injury (SCI) across six countries worldwide, controlling for socio-demographic and lesion-related sample characteristics and using a cross-culturally valid assessment.

Methods: Data from 243 persons with SCI from Australia, Brazil, Canada, Israel, South Africa and the United States were analyzed. QoL was measured using five satisfaction items from the World Health Organization Quality of Life Assessment. Cross-culturally valid, Rasch-transformed scores were used for comparison.

Results: Analysis of variance showed a significant difference in $\mathrm{Q}$ L between countries $(\mathrm{F}=3.938 ; \mathrm{df}=5 ; P=0.002)$. Shorter time since injury, no paid employment and living in Brazil were significant predictors of lower QoL, explaining $13 \%$ of variance in linear regression. Using multilevel regression with country as higher-order variable, time since injury and paid employment remained significant predictors and explained $18 \%$ of variance in QoL. The intraclass correlation coefficient $(0.05)$ indicates that $5 \%$ of the variability can be accounted for by country.

Conclusion: This study showed QoL differences between countries that could not be explained by differences in demographic and lesion-related characteristics. Results point to the relevance of reintegration of people with $\mathrm{SCl}$ into the workforce. Further international comparative research using larger samples is recommended.
\end{abstract}

Spinal Cord (2013) 51, 322-326; doi:10.1038/sc.2012.128; published online 13 November 2012

Keywords: spinal cord injuries; quality of life; employment; cross-cultural comparison

\section{INTRODUCTION}

Enhancing quality of life (QoL) is the ultimate goal of clinical as well as community-based management of spinal cord injury (SCI) and a key outcome of service provision. ${ }^{1,2}$ QoL has been found to be diminished following SCI. ${ }^{1,3}$

QoL in persons with SCI is consistently related to mental health, mobility, employment, overall participation, accessibility of the external environment, social support and coping. ${ }^{1-5}$ However, conflicting results have been reported on the relation of QoL to socio-demographic (age, gender and relationship status) and lesionrelated factors (level or completeness of lesion, time since injury, physical impairment and medical complications). ${ }^{2,5}$

QoL seems to vary by country. ${ }^{6}$ Conceptually, QoL has been defined as 'individuals' perceptions of their position in life in the context of the culture and value systems in which they live and in relation to their goals, expectations, standards and concerns.?

Domains of QoL in persons with SCI have been compared between eastern and western countries, ${ }^{8-10}$ and between developed countries within ${ }^{11}$ and beyond Europe ${ }^{12}$ using different measures. QoL is often operationalized using questions about satisfaction. Satisfaction with relationships to partner and friends, and satisfaction with self-care were found consistently similar across the examined countries ${ }^{9-11}$ when measured with the Life Satisfaction Questionnaire. ${ }^{13}$ Other areas of QoL (for example, satisfaction with one's financial situation or with work and leisure activities) differed between countries in some ${ }^{8,10,11}$ but not all analyses. ${ }^{9,11}$ In the existing studies, the differences in the sample characteristics have seldom been controlled for, different measurement instruments have been applied and the cross-cultural validity of the measures was not established in SCI. Thus, the available results have to be interpreted with caution, and it remains debatable if they indicate true differences in QoL among countries.

The overall objective of this study was to examine QoL of people with SCI across countries worldwide controlling for socio-demographic and lesion-related characteristics and using a cross-culturally valid assessment. The specific study questions were: (1) Does QoL of people with SCI differ between countries? (2) Is the country where a person with SCI lives a predictor of QoL when socio-demographic and lesion-related characteristics are considered at the same time? (3) Which socio-demographic and lesion-related characteristics are predictors of QoL irrespective of country?

\section{MATERIALS AND METHODS}

Study design and participants

A cross-sectional multi-centre study was conducted as part of an international co-operation project to develop the 'ICF Core Sets for Spinal Cord Injury.' ${ }^{14,15}$ The larger study involved 16 study centres from 14 countries worldwide and was conducted in 2006-2008.

${ }^{1}$ Swiss Paraplegic Research (SPF), Nottwil, Switzerland; ${ }^{2}$ Department of Health Sciences and Health Policy, University of Lucerne and SPF, Nottwil, Switzerland; ${ }^{3}$ University of Otago, Christchurch, New Zealand; ${ }^{4}$ Craig Hospital, Englewood, CO, USA; ${ }^{5}$ Loewenstein Rehabilitation Hospital, Raanana, Israel; ${ }^{6}$ Tel-Aviv University, Tel-Aviv, Israel; ${ }^{7}$ University of São Paulo, Medical School, São Paulo, Brazil and ${ }^{8}$ Rudolf Magnus Institute of Neuroscience, Center of Excellence for Rehabilitation Medicine, University Medical Center Utrecht, Rehabilitation Center De Hoogstraat, Utrecht, The Netherlands

Correspondence: Dr S Geyh, Swiss Paraplegic Research (SPF), Guido A. Zäch Strasse 4, CH-6207 Nottwil, Switzerland

E-mail: szilvia.geyh@paranet.ch

Received 6 April 2012; revised 28 August 2012; accepted 2 September 2012; published online 13 November 2012 
The current analysis includes data from seven participating rehabilitation facilities in Australia, Brazil, Canada, Israel (with two facilities), South Africa and the United States. These participating facilities of the larger study have agreed to add various QoL assessments to their data collections.

Participants were included irrespective of time since injury if they had sustained a SCI with an acute onset, they were at least 18 years old, the purpose and reason of the study was understood and an informed consent was signed. Subjects with traumatic brain injury or diagnosed mental disorders before SCI were excluded. Acute onset was defined as a trauma or non-traumatic event resulting in spinal cord dysfunction within 14 days of onset. Each facility undertook to recruit a consecutive sample of 40 outpatients with SCI.

\section{Measurement instruments}

Data were collected about socio-demographic and injury-related variables by a health professional (medical records and clinical interview) and about QoL using five items from the World Health Organization Quality of Life Assessment-BREF (WHOQOL-BREF). ${ }^{7,16}$ The WHOQOL items were selfadministered and handed out to the eligible participants either with the study information or on the occasion of data-collection interview conducted for the larger parent study. The five items cover overall QoL, satisfaction with health, daily activities, relationships and living conditions. They are scored from 1 (very dissatisfied) to 5 (very satisfied). The WHOQOL-BREF was specifically developed for cross-cultural use and is available in 36 languages. A previous study using the same data as the current study compared the metric properties of different QoL instruments in SCI across six countries and found the five selected WHOQOL items to be the best cross-culturally valid instrument. ${ }^{17}$ The five items fitted the Rasch model as shown by $\gamma^{2}$-tests $(P=0.088)$, the person reliability index was satisfactory $(0.78)$, the response categories were ordered and no cross-country bias was found through differential item functioning analyses.

The study design and materials were approved by the Ethics Committee of the Ludwig-Maximilian University Munich, as well as by the respective Ethics Committees/Institutional Review Boards for the study centres in each country.

\section{Analyses}

To characterize the study sample, descriptive statistics for socio-demographic (age, gender, years of education, employment status and relationship status) and lesion-related variables (level and completeness of injury, and time since injury) were calculated based on the available data set. The raw scores of the WHOQOL items were transformed using Rasch analyses according to the earlier study. ${ }^{17}$ This means that the person's level of QoL was estimated through the Rasch model based on the raw score values. These estimated person parameters were used for the further analyses. The person parameters are supposedly culture-free and build a normally distributed interval scale.

To investigate if there is a difference between countries in QoL, a one-way analysis of variance was performed. Post-hoc Tukey tests identified the countries that differ significantly from each other in pairwise comparisons.

To determine if country was associated with QoL while adjusting for sociodemographic and lesion-related variables, linear regression analyses were performed, first by only entering the countries as independent variables, and second, a full model was created with all variables.

To determine which socio-demographic and lesion-related variables are associated with QoL irrespective of country and accounting for the hierarchical structure of the data, a multilevel regression model was set up. ${ }^{18}$ Hereby, the socio-demographic and lesion-related data were modelled to be nested within the higher-level factor country. The country effect was considered random, whereas the other independent variables entered the model blockwise as fixed effects with a random intercept. The first model contained the sociodemographic variables, the second contained the lesion-related variables and a third model contained both blocks of fixed effects. Finally, a backward selection was performed, which discarded the variables that did not contribute to explain variance in $\mathrm{QoL}$

Pre-analyses of one-way interactions among all independent variables showed that these interactions contributed little or not at all to explain variance in $\mathrm{QoL}$, and therefore, they were omitted. Throughout the regression analyses, missing values were handled by casewise deletion and no imputation was performed.

\section{RESULTS}

Data from 243 persons with SCI from six countries entered the analyses. Table 1 summarizes the socio-demographic and lesionrelated characteristics of the study participants. Table 2 shows the raw scores of the five WHOQOL items, overall and by country. It also contains the mean Rasch-transformed QoL person parameter.

Figure 1 illustrates the difference in QoL among the studied SCI populations between the six countries depicting the box-plot of the country means and their s.d. The analysis of variance showed

\section{Table 1 Socio-demographic and SCl-related characteristics in the} sample $(n=243)$

Total Australia Brazil Canada Israel $\begin{aligned} & \text { South USA } \\ & \text { Africa }\end{aligned}$

\begin{tabular}{lrrrrrrr}
\hline $\begin{array}{l}\text { Age (years) } \\
\text { Mean }\end{array}$ & 41.4 & 36.4 & 36.7 & 47.0 & 45.6 & 35.8 & 42.8 \\
s.d. & 13.6 & 12.6 & 9.4 & 11.3 & 14.4 & 13.0 & 14.4
\end{tabular}

\section{Gender}

$\begin{array}{lccccccc}n & 242 & 39 & 34 & 34 & 71 & 30 & 34\end{array}$

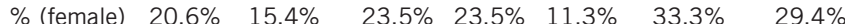

Relationship status ${ }^{a}$

$\begin{array}{llllllll}n & 241 & 39 & 34 & 33 & 71 & 30 & 34\end{array}$

$\begin{array}{llllllll}\% \text { (yes) } \quad 59.5 \% & 38.5 \% & 47.1 \% & 36.4 \% & 53.5 \% & 10.0 \% & 38.2 \%\end{array}$

\begin{tabular}{|c|c|c|c|c|c|c|c|}
\hline Mean & 13.0 & 14.6 & 10.7 & 14.8 & 12.8 & 106 & 142 \\
\hline s.d. & 4.0 & 2.1 & 6.1 & 2.7 & 4.0 & 3.4 & 2. \\
\hline
\end{tabular}

Paid employment ${ }^{\mathrm{b}}$

$\begin{array}{llllllll}n & 242 & 39 & 34 & 34 & 71 & 30 & 34\end{array}$

$\begin{array}{llllllll}\% \text { (yes) } \quad 33.5 \% & 41.0 \% & 38.2 \% & 38.2 \% & 31.0 \% & 23.3 \% & 29.4 \%\end{array}$

\section{Level of injury}

$\begin{array}{llllllll}n & 242 & 39 & 34 & 34 & 71 & 30 & 34\end{array}$

$\begin{array}{llllllll}\% & 45.9 \% & 10.3 \% & 70.6 \% & 47.1 \% & 62.0 \% & 36.7 \% & 35.3 \%\end{array}$

(paraplegia)

Completeness of injury ${ }^{\mathrm{c}}$

$\begin{array}{cccccccc}n & 221 & 28 & 34 & 26 & 70 & 29 & 34 \\ \% & 47.9 \% & 42.9 \% & 64.7 \% & 38.5 \% & 61.4 \% & 44.8 \% & 47.1 \%\end{array}$

(complete)

Etiology of injury

$\begin{array}{llllllll}n & 225 & 40 & 30 & 33 & 58 & 30 & 34\end{array}$

$\begin{array}{llllllll}\% & 92.4 \% & 90.0 \% & 100.0 \% & 78.8 \% & 96.6 \% & 86.7 \% & 100.0 \%\end{array}$

(traumatic)

Time since injury (years)

\begin{tabular}{llllllll} 
Mean & 11.6 & 4.9 & 8.3 & 18.8 & 11.9 & 11.6 & 14.9 \\
s.d. & 11.6 & 4.5 & 7.1 & 15.8 & 11.4 & 10.3 & 12.7 \\
\hline
\end{tabular}

Abbreviation: $\mathrm{SCl}$, spinal cord injury.

aRelationship status: defined 'yes' if married or cohabiting and 'no' if never married, separated, divorced or widowed.

'Paid employment: defined 'yes' if in paid employment or self-employed irrespective of hours per week and 'no' if not in paid employment or unemployed for health reasons, retired, per week and 'no' if not in paid
student, house-maker or other.

student, house-maker or other.
'Based on American Spinal Injury Association (ASIA) Impairment Scale. 
Table 2 Raw summary scores of the WHOQOL items, overall and by country, and Rasch-transformed mean level of overall QoL in logit units

\begin{tabular}{|c|c|c|c|}
\hline Country & $n$ & Mean & s.d. \\
\hline \multicolumn{4}{|l|}{ All countries } \\
\hline Raw summary score & 243 & 18.2 & 7.4 \\
\hline Rasch-transformed QoL level (logit) & & 0.5 & 1.1 \\
\hline \multicolumn{4}{|l|}{ Australia } \\
\hline Raw summary score & 40 & 17.2 & 6.0 \\
\hline Rasch-transformed QoL level (logit) & & 0.4 & 0.9 \\
\hline \multicolumn{4}{|l|}{ Brazil } \\
\hline Raw summary score & 34 & 17.3 & 7.5 \\
\hline Rasch-transformed QoL level (logit) & & 0.1 & 0.9 \\
\hline \multicolumn{4}{|l|}{ Canada } \\
\hline Raw summary score & 34 & 20.2 & 7.7 \\
\hline Rasch-transformed QoL level (logit) & & 0.8 & 1.3 \\
\hline \multicolumn{4}{|l|}{ Israel } \\
\hline Raw summary score & 71 & 19.3 & 7.1 \\
\hline Rasch-transformed QoL level (logit) & & 0.3 & 1.1 \\
\hline \multicolumn{4}{|l|}{ South Africa } \\
\hline Raw summary score & 30 & 14.1 & 6.7 \\
\hline Rasch-transformed QoL level (logit) & & 0.6 & 0.9 \\
\hline \multicolumn{4}{|l|}{ USA } \\
\hline Raw summary score & 34 & 19.6 & 8.5 \\
\hline Rasch-transformed QoL level (logit) & & 1.1 & 1.2 \\
\hline
\end{tabular}

Abbreviations: QoL, quality of life; WHOQOL, World Health Organization Quality of Life Assessment.

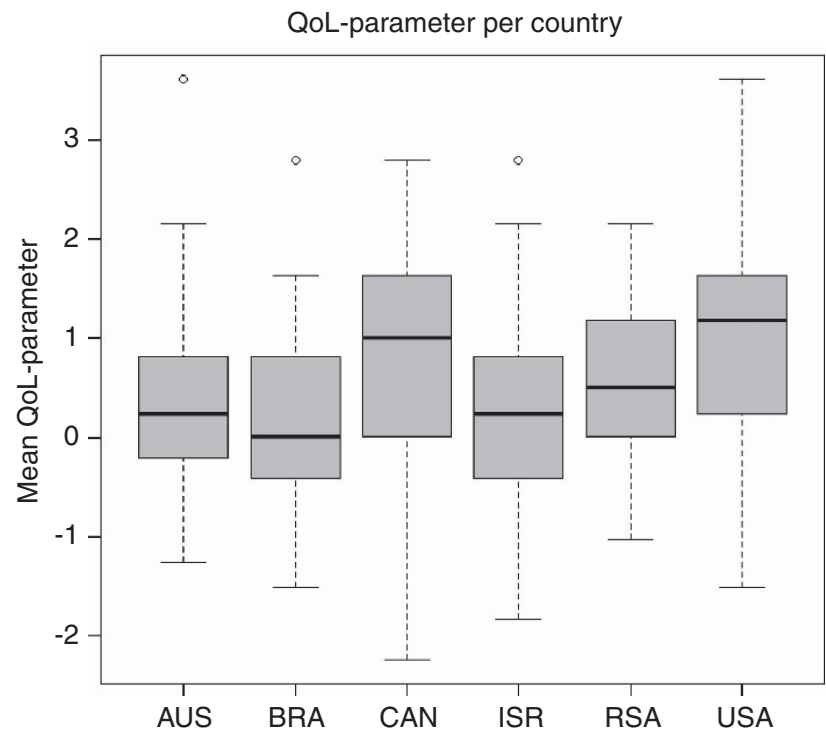

Figure 1 The mean level of QoL and its s.d. among the studied SCl populations in the six countries.

significant differences between countries $(\mathrm{F}=3.938 ; \mathrm{df}=5$; $P=0.002)$. The post-hoc Tukey tests indicated that the mean level of QoL in the United States was significantly higher compared with Brazil (mean difference $=0.97$; s.e. $=0.26 ; P=.004$ ) and Israel (mean difference $=0.77$; s.e. $=0.23 ; P=0.010)$.
Table 3 Linear regression explaining the dependent variable QoL

\begin{tabular}{|c|c|c|c|c|}
\hline & \multicolumn{2}{|c|}{ Countries only } & \multicolumn{2}{|c|}{ Full model } \\
\hline & $\beta$ & s.e. & $\beta$ & s.e. \\
\hline \multicolumn{5}{|l|}{ Socio-demographic variables } \\
\hline Age & & & -0.10 & 0.09 \\
\hline Gender & & & 0.18 & 0.17 \\
\hline Relationship status (yes/no) & & & -0.07 & 0.15 \\
\hline Years of education & & & 0.03 & 0.07 \\
\hline Paid employment (yes/no) & & & $0.38^{*}$ & 0.15 \\
\hline \multicolumn{5}{|l|}{ Injury-related variables } \\
\hline Level of injury (para/tetra) & & & -0.05 & 0.15 \\
\hline Completeness (complete/incomplete) & & & 0.12 & 0.14 \\
\hline Time since injury (years) & & & $0.30^{*}$ & 0.09 \\
\hline \multicolumn{5}{|l|}{ Country } \\
\hline Australia & -0.12 & 0.20 & -0.84 & 0.53 \\
\hline Brazil & $-0.35^{*}$ & 0.17 & $-1.13^{*}$ & 0.55 \\
\hline Canada & 0.00 & 0.21 & -0.90 & 0.55 \\
\hline Israel & -0.17 & 0.12 & -0.97 & 0.54 \\
\hline South Africa & 0.14 & 0.19 & -0.64 & 0.55 \\
\hline USA & $0.52^{*}$ & 0.17 & -0.35 & 0.52 \\
\hline$n$ & 208 & & 208 & \\
\hline$F$ & 2.734 & & 3.247 & \\
\hline $\mathrm{df}$ & $(6,202)$ & & $(14,194)$ & \\
\hline$P$ & $0.01^{*}$ & & $0.00^{*}$ & \\
\hline$R_{\text {adj }}^{2}$ & 0.05 & & 0.13 & \\
\hline
\end{tabular}

Significant values are marked bold with an asterisk $(P<0.05)$

Table 3 summarizes the linear regression models. The model including only the country variables explained $5 \%$ of the variance in QoL. Living in Brazil and living in the United States were significantly related to lower and higher QoL, respectively. Among all independent variables, three emerged as significant predictors of QoL, namely paid employment $(+)$, time since injury $(+)$ and living in Brazil ( - ). The full model explained 13\% variance.

Table 4 summarizes the results of the multilevel random intercept model to determine which socio-demographic and lesion-related variables are predictors of QoL irrespective of country. In the full model, being in a paid employment and time since injury were significantly and positively related to QoL. The full model explained $18 \%$ of variance in QoL. Omitting the nonsignificant variables using backward selection resulted in a model, which explained $17 \%$ of variance in QoL. The intraclass correlation coefficient indicated that $5 \%$ of the explained variability was accounted for by country.

\section{DISCUSSION}

This study found a small but statistically significant difference in QoL of participants with SCI from different countries using a crossculturally validated summary score. QoL was highest in the USA and lowest in Brazil. Participants who had been injured for a longer period of time and who worked in a paid employment reported higher QoL, irrespective of country.

\section{Country differences in QoL}

An overall effect of country of residence was found, but only the pairwise differences between the samples from the United States 
Table 4 Multilevel regression models explaining the dependent variable QoL

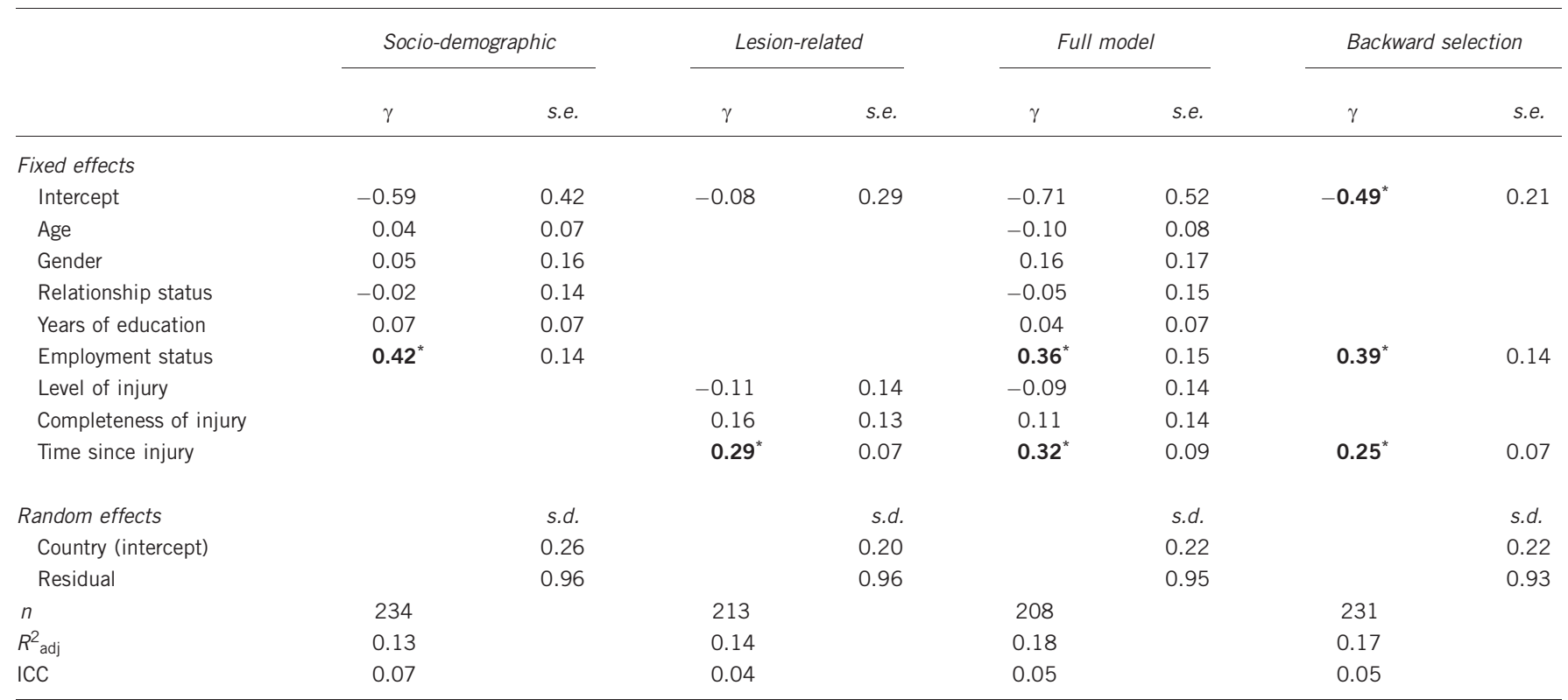

Abbreviations: $\gamma$, multilevel regression coefficient gamma; ICC, intraclass correlation coefficient; QoL, quality of life.

Significant values are marked bold with an asterisk $(P<0.05)$.

versus Brazil and Israel were significant. Because of the small sample size per country, only the largest differences, of 0.8 logit or more, were statistically significant.

Comparing the results to international research on QoL in non-SCI populations reveals divergences of cross-country comparisons depending on the measures used. One study used the full WHOQOL-BREF in 23 countries. ${ }^{19}$ It did not include Canada and South Africa, but considering the four other countries in our study, they found higher QoL in Australia than in Brazil, Israel and the United States, in this rank order. In a worldwide survey of 41 nations, representative samples responded to a single life-satisfaction question. ${ }^{20}$ Australia and Israel were not represented, but in Canada, higher life satisfaction was reported than in the United States, Brazil and South Africa, in this rank order.

We found only five earlier studies comparing QoL of persons with SCI across countries, and these showed deviating results. Data from four European countries showed no significant difference in life satisfaction. ${ }^{11}$ A comparison between Sweden and Australia showed no significant difference on global QoL measured with a visual analogue scale. ${ }^{12}$ Three studies compared a Western and an Eastern country: United Kingdom versus China, ${ }^{10}$ the United States versus China $^{9}$ and Sweden versus Japan. ${ }^{8}$ These studies showed higher lifesatisfaction scores in the Western country on several life domains. ${ }^{8,10}$ Our finding of a small but statistically significant country effect of QoL fits in the range of these findings.

Gainful employment was a significant predictor of QoL in this sample, independent of country, socio-demographic and lesioncharacteristics, as well as education. Research has consistently shown the importance of employment, and the broader concept of participation, for QoL. ${ }^{1-3}$ Employment benefits include not only a better financial status, but also the person's self-realization, self-esteem, health and better overall social integration. ${ }^{21}$ Future studies should include this type of variable to further analyze the beneficial components of paid employment on QoL in SCI. This also points to the relevance of reintegration to work and occupational rehabilitation interventions for people with SCI.
The current study found time since injury to be positively related to QoL. Participants displayed a wide range of time since injury (between 1 month and 50 years), which also differed between countries. However, the effect of time since injury has been controlled for statistically in the regression models. Other studies also show life satisfaction to be related to QoL in the early phase of living with $\mathrm{SCI},{ }^{22}$ whereas on the long term, deviating patterns of increase or stability have been reported. ${ }^{12}$

No associations between the examined lesion-related characteristics and QoL were found, which is consistent with the literature that impairments due to SCI do not affect QoL directly, but rather through their impact on activities and participation. ${ }^{1,2}$ Furthermore, we did not find an association of the examined socio-demographic characteristics age, gender, relationship status and education on QoL in this sample, which is in line with research in SCI populations from different countries. ${ }^{23-25}$

\section{Strengths of the study}

This study adds to the literature by using an instrument that has shown its cross-cultural validity. Further, a larger number of countries and geographical spread was included compared with existing studies. A strength is also the use of multilevel modelling, which is more appropriate, given the grouped structure of the data.

\section{Limitations of the study}

Although the WHOQOL-BREF has been found a suitable measure of QoL following SCI, ${ }^{26,27}$ the summary score of the five WHOQOL items is only a global indication of QoL, and does not provide information on the domains of life with which a person with SCI might be more or less satisfied. Studies that used domain-specific measures can provide more concrete information on areas of dissatisfaction and thereby guidance for rehabilitation practice. ${ }^{8,10,13}$

Second, potentially relevant correlates of QoL, for example, overall participation, social support or self-efficacy beliefs ${ }^{1-3,22}$ were not available from the data collections. Consequently, the amount of variance in QoL that could be explained was small. Future studies 
should consider comprehensive data collection including environmental and personal factors to enhance the explanation of QoL after SCI.

Third, the sample of countries was small and does not cover all world regions and cultural variation. In addition, for most countries, the data collection was restricted to one participating study centre only. Because of the limitations of the sampling procedure, the representativity of the samples cannot be assumed. Mainly, persons with traumatic SCI have been included in the study, and it is possible that centres with a high standard of care and persons with high QoL were more likely to participate, which could have led to an underestimation of country differences. Therefore, the generalizability of the findings is limited.

\section{Recommendations}

The results of this study contribute to the knowledge and might inspire future studies. The aim of cross-cultural QoL research in SCI would be to understand the variation in SCI outcomes in different contexts. Country comparisons could help identify if contextual factors at different levels, for example, insurance systems, health and rehabilitation services, societal values and norms, and so on, which diverge in different countries, could be improved to enhance QoL of people with SCI. Finally, studies using larger sample sizes and longitudinal designs are needed to demonstrate clinically relevant differences.

\section{DATA ARCHIVING}

There were no data to deposit.

\section{CONFLICT OF INTEREST}

The authors declare no conflict of interest.

\section{ACKNOWLEDGEMENTS}

This study was funded by the Swiss Paraplegic Research (SPF), Nottwil, Switzerland. We thank all people with SCI who took part in the data collection. The contribution of all study centres and participating health professionals is much appreciated. Especially, we thank the regional coordinators of the study 'Development of ICF Core Sets for Spinal Cord Injury' Angela Chu, Gabi Zeilig, Fin Biering-Sorensen, Michael Baumberger, Apichana Kovinda and Rob Campbell, as well as the study coordinators Monika Scheuringer, Inge Kirchberger and Alarcos Cieza for their work in organizing and conducting the data collections.

1 Dijkers MP. Quality of life of individuals with spinal cord injury: a review of conceptualization, measurement, and research findings. J Rehabil Res Dev 2005 42: 87-110.

2 Hammell KW. Exploring quality of life following high spinal cord injury: a review and critique. Spinal Cord 2004; 42: 491-502.

3 Post M, Noreau L. Quality of life after spinal cord injury. J Neurol Phys Ther 2005; 29: $139-146$.
4 Dowler R, Richards JS, Putzke JD, Gordon W, Tate D. Impact of demographic and medical factors on satisfaction with life after spinal cord injury: a normative study. J Spinal Cord Med 2001; 24: 87-91.

$5 \mathrm{Ku} \mathrm{JH}$. Health-related quality of life in patients with spinal cord injury: review of the short form 36-health questionnaire survey. Yonsei Med J 2007; 48: 360-370.

6 Diener E, Suh EM, Smith H, Shao L. National differences in reported subjective wellbeing: why do they occur? Soc Indic Res 1995; 34: 7-32.

7 WHOQOL Group. The World Health Organization Quality of Life Assessment (WHO QOL): development and general psychometric properties. Soc Sci Med 1998; 46 1569-1585.

8 Ide M, Fugl-Meyer AR. Life satisfaction in persons with spinal cord injury: a comparative investigation between Sweden and Japan. Spinal Cord 2001; 39 387-393.

9 Hampton NZ, Marshall A. Culture, gender, self-efficacy, and life satisfaction: a comparison between Americans and Chinese people with spinal cord injuries. J Rehabil 2000; 66: 21-28.

10 Songhuai L, Olver L, Jianjun L, Kennedy P, Genlin L, Duff J et al. A comparative review of life satisfaction, quality of life and mood between Chinese and British people with tetraplegia. Spinal Cord 2009; 47: 82-86.

11 Kennedy P, Lude P, Taylor N. Quality of life, social participation, appraisals and coping post spinal cord injury: a review of four community samples. Spinal Cord 2006; 44 95-105.

12 Kreuter M, Siosteen A, Erkholm B, Bystrom U, Brown DJ. Health and quality of life of persons with spinal cord lesion in Australia and Sweden. Spinal Cord 2005; 43: $123-129$

13 van Koppenhagen CF, Post MW, van der Woude LH, de Witte LP, van Asbeck FW, de Groot $\mathrm{S}$ et al. Changes and determinants of life satisfaction after spinal cord injury: a cohort study in the Netherlands. Arch Phys Med Rehabil 2008; 89: 1733-1740.

14 Biering-Sorensen F, Scheuringer M, Baumberger M, Charlifue SW, Post MW, Montero F et al. Developing core sets for persons with spinal cord injuries based on the international classification of functioning, disability and health as a way to specify functioning. Spinal Cord 2006; 44: 541-546.

15 Cieza A, Kirchberger I, Biering-Sorensen F, Baumberger M, Charlifue S, Post MW et al. ICF core sets for individuals with spinal cord injury in the long-term context. Spinal Cord 2010; 48: 305-312.

16 WHOQOL Group. Development of the World Health Organization WHOQOL-BREF quality of life assessment. The WHOQOL group. Psychol Med 1998; 28: 551-558.

17 Geyh S, Fellinghauer BAG, Kirchberger I, Post MW. Cross-cultural validity of four quality of life scales in persons with spinal cord injury. Health Qual Life Outcomes 2010; 8: 94

18 Zuur AF, leno EN, Walker NJ, Saveliev AA, Smith GM. Mixed Effects Models and Extensions in Ecology with R. Springer: New York, 2009.

19 Skevington SM, Lotfy M, O'Connell KA. The World Health Organization's WHOQOL BREF quality of life assessment: psychometric properties and results of the international field trial. A report from the WHOQOL group. Qual Life Res 2004; 13: 299-310.

20 Diener E, Suh EM. National differences in subjective well-being. In: Kahnemann D, Diener E and Schwarz N (eds). Well-Being the Foundations of Hedonic Psychology. Russell Sage Foundation: New York, 1999.

21 Lidal IB, Huynh TK, Biering-Sorensen F. Return to work following spinal cord injury: review. Disabil Rehabil 2007; 29: 1341-1375.

22 van Leeuwen CM, Kraaijeveld S, Lindeman E, Post MW. Associations between psychological factors and quality of life ratings in persons with spinal cord injury: a systematic review. Spinal Cord 2012; 50: 174-187.

23 Gurcay E, Bal A, Eksioglu E, Cakci A. Quality of life in patients with spinal cord injury. Int J Rehabil Res 2010; 33: 356-358.

24 Lidal IB, Veenstra M, Hjeltnes N, Biering-Sorensen F. Health-related quality of life in persons with long-standing spinal cord injury. Spinal Cord 2008; 46: 710-715.

25 Mortenson WB, Noreau L, Miller WC. The relationship between and predictors of quality of life after spinal cord injury at 3 and 15 months after discharge. Spinal Cord 2010; 48: 73-79.

26 Hill MR, Noonan VK, Sakakibara BM, Miller WC. Quality of life instruments and definitions in individuals with spinal cord injury: a systematic review. Spinal Cord 2010: 48: 438-450.

27 Jang Y, Hsieh CL, Wang YH, Wu YH. A validity study of the WHOQOL-BREF assessment in persons with traumatic spinal cord injury. Arch Phys Med Rehabil 2004; 85 1890-1895. 